\title{
PENDIDIKAN KRISTEN DI ABAD ERA GLOBALISASI: STRATEGIC TEACHING AND LEARNING YANG BERORIENTASI KEPADA STUDENTS-CENTERED
}

\author{
Rufina Leong*1 \\ ${ }^{1}$ Malaysia Evangelical Theological Seminary, Miri, Sarawak. \\ *rufleong@hotmail.com
}

\begin{abstract}
Learning strategies have the purpose of giving awareness to educators to increase their knowledge of technological development skills from the era of globalization. The question that arises: What is Christian Education? What are the effective Christian Education learning strategies? What are the challenges, constraints of implementing Christian Education, and how to overcome them? The answer is: (1) Christian education is a student-centered learning process based on elements of communication, collaborative, critical thinking, creativity, and the application of pure values and ethics. (2) Christian Education learning strategies can be done in accordance with the context of students in the classroom with the following rules: teachers determine the instructor learning process strategy, teachers give time and opportunity, teachers give clear instructions to students, teachers give trust and guidance to students and teachers give students the right to learn. (3) The challenges and constraints of implementing Christian Education and how to overcome it are: First, teachers (lecturers) need to be aware of the importance of diversifying teaching and learning methods to be in line with 21st century education in fulfilling their duties and responsibilities for students. Second, teachers should always be proactive, self-assessing, prepared, confident and take the initiative to strive to improve skills and produce effective teaching techniques that are able to attract students.
\end{abstract}

Keywords: learning strategies, student-centered, learning models, teachers (lecturers)

\begin{abstract}
Abstrak
Strategi pembelajaran mempunyai tujuan memberi kesadaran kepada warga pendidik meningkat pengetahuan keterampilan perkembangan tekonologipada era globalisasi. Persoalan yang timbul: Apa itu Pendidikan Kristen? Bagaimanakah strategi pembelajaran Pendidikan Kristen yang efektif? Bagaimanakah cabaran, kekangan melaksanakan Pendidikan Kristen, dan cara mengatasinya? Jawabnya adalah: (1) Pendidikan Kristen merupakn proses pembelajaran yang berpusatkan murid berteraskan elemen komunikasi, kolaboratif, pemikiran kritis, kreativiti, dan aplikasi nilai murni dan etika. (2) Strategi pembelajaran Pendidikan Kristen dapat dilakukan sesuai dengan konteks murid di kelas dengan kaidah-kaidah sebagai berikut: guru menentukan strategi proses belajar pengajar, guru beri masa dan peluang, guru memberikan arahan jelas kepada murid, guru memberi kepercayaan dan bimbingan kepada murid, dan guru memberikan hak murid untuk belajar. (3) Cabaran dan kekangan melaksanakan Pendidikan Kristen dan cara mengatasinya adalah: Pertama, guru-guru (pensyarah-pensyarah) perlu sadar akan kepentingan mempelbagaikan kaedah pengajaran dan pembelajaran agar selari dengan pendidikan abad ke-21 dalam menunaikan tugas dan tanggungjawab mereka demi kemenjadian murid. Kedua, guru harus sentiasa bersikap proaktif, menilai diri, bersedia, berkeyakinan dan mengambil inisiatif untuk berusaha meningkatkan kemahiran dan menghasilkan teknik pengajaran berkesan yang mampu menarik minat murid.
\end{abstract}

Kata Kunci: strategi pembelajaran, perpusat kepada murid, model pembelajaran, guru-guru (pensyarah-pensyarah) 


\section{PENDAHULUAN}

Selaras dengan Kementerian Pendidikan Malaysia berusaha mengangkat Pendidikan bertaraf dunia sebagai wacana dalam Dasar Pendidikan Negara dan meletakkan proses Pendidikan sebagai satu bidang yang penting dalam kehidupan seharian. ${ }^{1} \quad$ Seminari sudah semestinya mengikut peredaran zaman dalam memastikan mahasiswa-mahasiswi yang dikeluarkan bukan saja mempunyai ilmu pengetahuan akitabiah, tetapi juga menguasai kemahiran teknologi era globalisasi pada masa kini. Untuk menghadapi cabaran globalisasi, sebagai rakyat Malaysia perlu dilengkapi dengan asas Pendidikan dan latihan yang kukuh serta mempunyai pelbagai kemahiran umum termasuk kebolehan berkomunkasi dengan berkesan dan mempunyai kepimpinan yang mantap, mampu berpikir secara kritis dan kreatif, dan menguasai Bahasa.

Sehubungan dengan itu pensyarahpensyarah di seminari juga tidak boleh ketinggalan dalam perkembangan teknologi global yang semakin berkembang. Sehubungan dengan itu tenaga pengajar bukan saja mempunyai ilmu tetapi strategi pengajaran melalui pemilihan dan perancangan dalam menentukan pendekatan, kaedah, teknik dan aktivitas dalam sesuatu pengajaran untuk mencapai objektif pengajaran. Aktivitas-aktivitas pengajaran mesti berorientasi kepada kooperatif and kolaboratif, yang berpusat kepada studentscentred dan not teachers-centered.

Pengajar menekanan kepada 4C (Communication, Collaboration, Creative and Critical thinking) dalam menghadapi

\footnotetext{
${ }^{1}$ Malaysia (2013), "Pelan Pembangunan Pendidikan Malaysia 2013-2025" (Putrajaya: Bahagian Pembangunan Kurikulum), https://www.imls.gov.
}

generasi abad ke-21 akan menjadi insan yang boleh menghadapi cabaran real world. Tenaga pengajar harus tidak lagi give me a fish and I have a fish for the day, tetapi teach me to fish and I have fish for a lifetime. Dengan demikian bahwa Strategic Learning dapat didefinisikan sebagai "menggunakan evaluasi untuk membantu organisasi atau kelompok belajar dengan cepat dari pekerjaan mahasiswa sehingga mereka dapat belajar dari dan menyesuaikan strategi pembelejarannya. Ini berarti mengintegrasikan evaluasi dan pemikiran evaluatif ke dalam pengambilan keputusan strategis dan membawa data tepat waktu ke meja untuk refleksi dan penggunaan." Schumaker dan Deshler memperlengkap bahwa strategi pembelajaran adalah "an individual's approach to a task. It includes how a person thinks and acts when planning, executing, and evaluating performance on a task and its outcomes."2

Tujuan penulisan artikel adalah peneliti memperlihat gambaran dari prinsipprinsip yang mendasari dari strategic learning dengan mengemukakan persoalanpersoalan berikut: Apa itu Pendidikan Kristen? Bagaimanakah strategi pembelajaran Pendidikan Kristen yang efektif? Bagaimanakah cabaran, kekangan melaksanakan Pendidikan Kristen, dan cara mengatasinya?

\section{METODE}

Metode penulisan artikel ini adalah jenis artikel konseptual atau artikel hasil pemikiran, bukan artikel hasil penelitian. Russel mengatakan bahwa penelitian konseptual adalah merupakan analisa

${ }^{2}$ J.B. Schumaker \& D.D. Deshler, "Teaching Adolescents to be Strategic Learners", Teaching Adolescents with Disabilities: Accessing the General Education Curriculum (Thousand Oaks, CA: Corwin Press, 2006), 121. 
pemikiran terhadap fenomena-fenomena masalah yang muncul. ${ }^{3}$ Semula penulis meneliti bahan-bahan literatur yang berkaitan dengan permasalahannya. Bahan yang dikumpulkan tentu saja berbagai hal adalah bahan-bahan yang mendukung dan menolak pemikiran yang sedang penulis kaji tetapi bahan mendukung yang berupa hasil penelitian atau artikel atau buku dapat digunakan dalam artikel konseptual. Artikel konseptual berbicara bukan sekadar kumpulan kutipan dari sejumlah artikel, tetapi memasukan memikiran kritis penulisanya.

\section{PEMBAHASAN \\ Pendidikan Kristen}

Pembelajaran era globalisasi ialah suatu transformasi dalam dunia Pendidikan di mana kaedah Pengajaran dan Pembelajaran secara konvensional seperti chalk and talk kepada kaedah pembelajaran dan pemudahcaraan yang lebih dinamik dan kreatif dengan kandungan pembelajaran yang relevan dan sesuai dengan perkembangan semasa. Dengan itu semua guru perlu bersedia menerima segala perubahan dan dapat mengurus perubahan tersebut dengan cakap dan berkesan karena guru (pensyarah) merupakan "Kumpulan Pelaksana "Pelaksana". Guru-guru atau pensyarah-pensyarah mempunyai tanggung jawabn untuk melaksanakan perubahan tersebut. $^{4}$

Pada masa yang sama, guru perlu menyadari bahwa dunia Pendidikan kini

${ }^{3}$ B.H. Russel, Social Research Methods: Qualitative and Quantitative Approaches (Thousand Oaks, CA: Sage Publications, 2000), 36.

${ }^{4}$ Nur Syahfika Abdul Shukor \& Zolkepli Harun, "Cabaran Penerapan Pembelejaran Abad ke21 dalam Mata peljaran Sains", Procesing 1(43) (Malaysia: Fakulti Pendidikan Universiti Kebangsaan Malaysia). perlu perubahan ke arah perkembangan teknologi siber dan berpusatkan murid agar menarik minat murid untuk menghayati mata pelajaran yang dipelajari sekaligus memantapkan mereka untuk dapat mempunyai kemahiran berpikir aras tinggi. Dengan demikian bahwa guru berperanan sebagai perancang, pengawal, pembimbing, pendorong dan penilai untuk memperkembangkan potensi murid secara menyeluruh dan menghasilkan pencapaian murid pada tahap optimum secara berterusan. Seterusnya peranan murid pula adalah sebagai pembelajar aktif untuk menguasaian kemahiran, pengetahuan, dan mengamalkan nilai positif. Maka sesuailah sekiranya seorang guru mengamalkan pembelajaran pada era globalisasi teknologi ini ke bilik kelas masing-masing agar kriteria penilaian tercapai sekaligus. Kriteria penilaian adalah merealisasikan enam aspirasi murid yaitu: (1) murid yang berpengetahuan, (2) murid yang mempunyai kemahiran berpikir, (3) murid yang mempunyai kemahiran untuk memimpin, (4) murid yang mempunyai kemahiran dwibahasa, (5) murid yang mempunyai etika dan kerohanian, dan (6) akhir sekali murid yang memaparkan identity nasional.

Pendidikan Kristen adalah proses Allah hadir dalam belajar mengajar, sudah dapat dipastikan bahwa pembelajaran tidak akan berhasil apalagi berhasil secara maksimal. Dengan demikian, Pendidikan Agama "lebih dari kegiatan "yang berurusan dengan soal penggarapan kognitif (akal), melainkan juga menggarap bidang afektif (moral) dan psikomotoris (keterampilan). Dengan kata lain, Pendidikan Agama bukan saja sebagai usaha penyaluran ilmu, melainkan proses pengubahan hidup berdasarkan kehendak Allah. Penguasaan 
pengetahuan hanyalah batu loncatan untuk menghasilkan perubahan hidup. ${ }^{5}$

Pendidikan Kristen menjadi sebagai proses pembelajaran yang berpusatkan kepada murid. Terdapat beberapa elemen yang diterapkan, yaitu: komunikasi, kolaboratif, pemikiran kritis, kreativiti, aplikasi nilai murni, dan etika. Elemenelemen ini juga disebut sebagai standard asas dalam pendidikan Kristen era globalisasi. Malaysia merupakan sebuah negara yang berkembang pesat seiring dengan ledakan globalisasi pada masa kini. Dalam menuju ke arah pendidikan bertaraf dunia, Malaysia perlu membawa suatu perubahan yang akan memberi kesan kepada dunia pendidikan. Oleh itu, Kementerian Pendidikan Malaysia (KPM) telah meneliti perkara-perkara yang perlu dilaksanakan dan berusaha untuk menjayakan usaha tersebut. Bersesuaian dengan matlamat dan zaman, KPM telah melaksanakan pembelajaran abad ke-21 bermula pada tahun $2014 .^{6}$

Kini, pendidikan Kristen telah menjadi satu isu yang hangat dalam dunia pendidikan karena ia dilihat mampu memenuhi keperluan pendidikan pada masa kini, di samping membawa perubahan baru dalam dunia pendidikan. Pendidikan Kristen dikatakan sebagai proses pembelajaran yang berpusatkan kepada murid.

\section{Komunikasi}

Komunikasi merupakan suatu proses pertukaran maklumat daripada individu kepada individu yang lain. Dalam konteks pendidikan, komunikasi merujuk kepada perbuatan yang berlaku di antara guru dan murid atau murid dan murid untuk

\footnotetext{
${ }^{5}$ Harianto GP, Teologi PAK (Yogyakarta: Andi, 2017), 25-26.

${ }^{6} \mathrm{https}: / / \mathrm{www}$. pendidik2u.my/pembelajaranabad-ke-21-pak21/.
}

berkongsi ilmu yang dipahami bersama rekan-rekan lain. Ini yang dikatakan sebagai komunikasi berpusatkan murid. Namun begitu, jika guru tidak memainkan peranannya dengan baik, komunikasi yang berkesan tidak akan terhasil semasa proses pembelajaran berlangsung.

Sebagai contoh, guru ingin mewujudkan komunikasi dua arah dalam kalangan murid-muridnya melalui pembentangan mengenai tajuk yang diberi dan meminta murid-murid untuk berbincang di dalam kumpulan masing-masing sebelum memulai pengajaran di kelas. Pada masa yang sama, guru juga perlu memainkan peranannya sebagai fasilitator kepada muridnya. Guru hendaklah memantau cara penyampaian murid-muridnya supaya pembentangan tersebut menjadi pembentangan yang berkesan serta dapat memberikan maklumat yang berkualitas kepada murid lain.

Bagi pembangunan diri murid itu sendiri, guru boleh memberi komentar yang membina dari segi penggunaan bahasa badan, nada suara, tulisan, cara bertanya kepada rekan-rekan lain, cara menjawab soalan yang diajukan, cara memberi maklum balas jika rekan bertanya soalan yang tidak dijangka dan sebagainya. Oleh yang demikian, murid-murid dapat membina keyakinan diri semasa berinteraksi bersama rekan-rekan lain karena mereka mampu mendengar dan memberi respon, mampu untuk menerangkan dengan jelas dan ringkas, memahami kaedah-kaedah untuk menyampaikan maklumat dan juga mereka akan merasa lebih terbuka jika diminta untuk mengulas suatu topik.

\section{Kolaboratif}

Kolaboratif merujuk kepada sesuatu yang dilakukan secara bersama-sama atau 
berkumpulan. Kolaboratif dalam dunia pendidikan pula adalah kerjasama yang wujud antara guru dan murid atau murid dan murid secara aktif dan menyeluruh, di mana, ia melibatkan pertukaran idea, pendapat atau pengetahuan antara muridmurid. Bagi elemen ini, guru perlu memahami gaya pembelajaran muridnya.

Harianto GP mengatakan bahwa coorperative learning is the right model for improving one's character. This learning process is in a group so that members of the group to set an example for others. This condition is a proper process of improving one's character. This process requires cooperation among the group members for each member improving character homogeneous background. ${ }^{7}$

Ada murid yang tidak suka membuat tugas, sehingga tugas-tugasnya menumpuk disebabkan beberapa faktor. Guru perlu mempunyai strategi yang menarik agar para murid rajin membuat tugas yang diberikan oleh gurunya. Guru bertanggungjawab untuk menyelesaikan masalah-masalah tersebut. Guru harus dapat membantu murid-murid dalam meningkatkan pencapaian mereka dari masa ke masa. Sekiranya wujud suasana kelas yang kolaboratif, maka guru akan membawa kepada metakognitif, yaitu: kesadaran murid-murid tentang perkara yang diketahui dan tidak diketahui semasa proses pembelajarannya. Murid dapat menjadi mandiri dan mampu menyelesaikan tugastugas yang diberikan oleh gurunya.

Melalui kolaborasi, guru boleh menerapkan beberapa nilai positif dalam diri murid itu sendiri, seperti bertanggungjawab terhadap tugasan dalam

${ }^{7}$ Harianto GP, (2016), “Quality Learning Cooperative With Pattern Collaborative to Improve the Character", Jurnal Tekpen, 1(1), 146. kumpulan, penglibatan aktif atau seimbang, bersikap terbuka untuk menerima idea dan pandangan rekan-rekan lain serta mengeratkan hubungan silaturrahim dalam kalangan mereka. Jadi, guru adalah insan yang paling sesuai untuk melakukan sesuatu perkara dalam memancing emosi dan perhatian murid-muridnya.

\section{Kreativitas}

Kreativitas merujuk kepada sesuatu proses yang berlaku, di mana, ia melibatkan penghasilan sesuatu yang baru, berguna dan juga berkualitas. Elemen ini juga merupakan salah satu elemen yang penting untuk diterapkan dalam diri murid. Hal ini demikian kerana kreativitas bersifat meluas yang melibatkan sesuatu projek dan juga pemikiran murid itu sendiri. Mereka perlu berpikir di luar kotak untuk menghasilkan sesuatu ciptaan yang baru dan berguna.

Dalam kelas era globalisasi, guru boleh meminta muridnya untuk menghasilkan sesuatu produk yang unik, yaitu produk yang lain daripada produk yang sudah ada. Perkara ini amat bersesuaian dengan ciri-ciri kelas abad ke 21 adalah pembelajaran berpusatkan murid. Walau bagaimanapun, murid-murid masih memerlukan bimbingan daripada seorang guru adalah sebagai berikut: (1) Guru perlu menilai sama ada produk yang dihasilkan oleh murid adalah sebuah produk yang baru atau sedia ada, di samping meneliti keunikan dan keaslian produk itu sendiri. Komenentar yang praktikal perlu diberi supaya murid dapat membuat penambahbaikan terhadap produk ciptaannya. (2) Guru perlu meminta murid untuk memberi penerangan tentang produk yang dihasilkan. Dari situ, guru boleh menilai sama dengan murid tersebut mampu memberi produk yang kukuh atau tidak 
dalam mempertahankan keistimewaan produk ciptaannya. Di sini guru boleh menerapkan unsur pemikiran kritis dengan meminta murid-murid lain untuk turut memberi pandangan dan idea bagi tujuan penambahbaikan terhadap produk tersebut. Oleh yang demikian, setiap murid dapat menjabarkan berbagai idea yang mereka miliki. (3) Guru hanya perlu membimbing muridnya untuk berpikir mengenai sesuatu perkara dari berbagai berbagai sudut pandang. Dengan itu, bahwa strategi pembelajaran apa yang dilakukan oleh guru akan menghasilkan murid-murid yang berani mengambil risiko, seperti berani untuk mengemukakan idea tanpa merasa bimbang terhadap kritikan yang bakal diterima dan para murid mampu untuk berpandangan jauh tentang sesuatu perkara.

\section{Pemikiran Kritis}

Ada sesetengah pihak seringkali keliru dengan istilah pemikiran kritis dan kreatif. Ia merupakan dua istilah yang berbeda. Pemikiran kritis merujuk kepada keupayaan individu untuk membuat penilaian mengenai sesuatu perkara, termasuk kebaikan dan kelemahannya. Dari sudut pendidikan, pemikiran kritis berlaku apabila murid-murid mulai mengembangkan pemikiran mereka untuk menilai idea-idea yang diterima secara rasional dan membuat pertimbangan mengenai idea tersebut melalui penggunaan alasan-alasan yang wajar. Pemikiran kritis boleh dihasilkan dengan berkesan melalui beberapa cara, seperti penggunaan sumber yang meluas. Sumber yang meluas merujuk kepada maklumat yang diperoleh oleh murid-murid. Oleh itu, adalah: (1) guru perlu memantau sama ada maklumat yang dicari oleh murid bersesuaian dengan topik pembelajaran ataupun tidak. (2) Guru juga perlu memastikan muridnya mahir untuk mencari maklumat yang berkaitan dan menilai sama ada maklumat yang diperoleh itu cukup atau tidak untuk melaksanakan tugasan yang diberi.

Kemudian, pemikiran kritis yang baik dihasilkan oleh murid, oleh guru dapat kembangkan idea dan pendapat muridmuridnya. Di dalam kelas abad ke-21, guru seharusnya menggalakkan murid untuk memberi pandangan tentang sesuatu topik yang sedang dibincang. Pandangan yang tidak tersasar daripada topik perbincangan harus diterima oleh guru supaya muridmurid merasa dihargai dalam mengutarakan idea-idea mereka.

Dari situ, guru boleh menilai tahap pemikiran muridnya terhadap sesuatu perkara. Adakah mereka melihat sesuatu perkara daripada sudut yang berbeda? Jika ya, ini bermakna murid tersebut telah berpikir secara kritis.

Seterusnya, guru juga boleh menerapkan elemen perbahasan semasa proses pengajaran dan pembelajaran berlangsung. Guru perlu meminta murid untuk memberikan idea atau pandangan mengenai tajuk pembelajaran pada hari tersebut. Idea yang diberi tidak perlu dibincangkan, tetapi, guru perlu bertanya kepada murid mengapa idea tersebut yang diberikan.

Guru juga perlu memberi batasan kepada murid-murid lain untuk membahas idea tersebut supaya ide-ide mereka tidak meluas dari berbagai pandangan dan pengetahuan. Oleh yang demikian, elemen pemikiran kritis berjaya diterapkan dalam diri murid-murid melalui sesi proses pengajaran dan pembelajaran yang dilaksanakan oleh guru. Ia berlaku hanya dengan penerapan beberapa perkara penting, seperti memiliki maklumat yang sesuai 
berdasarkan tajuk, mempunyai sikap ingin tahu dan bersedia untuk meneroka sesuatu topik melalui pembacaan, soal jawab bersama guru dan rakan serta melaksanakan aktivitas hands-on bagi mendapatkan sesuatu maklumat, di samping mampu membuat sesuatu keputusan berdasarkan maklumat-maklumat yang diperoleh dan berupaya untuk mempertahankan keputusan tersebut dengan menggunakan bukti-bukti yang berasas.

Murid yang berpikiran kritis adalah murid yang berpikiran terbuka, di mana, mereka mudah untuk menerima pandangan atau idea yang dikemukakan oleh rekanrekan lain dan tidak mengabaikan idea yang diterima. Dengan ini, guru-guru perlu mengenali setiap muridnya supaya elemen ini lebih mudah diterapkan semasa proses belajar mengajar berlangsung.

\section{Nilai Murni dan Etika}

Nilai murni boleh ditafsirkan sebagai tingkah laku yang baik, beradab dan menjaga tatasusila, manakala, etika pula merujuk kepada keperibadian atau perwatakan seseorang. Dalam dunia pendidikan, elemen ini amat penting untuk diterapkan dalam diri murid-murid supaya ia dapat membentuk jati diri yang tinggi. Guru merupakan insan yang paling rapat dengan murid ketika mereka berada di sekolah. Oleh itu, guru seharusnya berusaha untuk menerapkan nilai-nilai yang positif dalam diri murid-murid semasa sesi proses belajar mengajar berlangsung.

Ketika sesi proses belajar mengajar berlangsung, guru boleh meminta murid untuk menyatakan nilai murni yang bersesuaian dengan topik pembelajaran pada hari tersebut. Kemudian, guru perlu menilai sama ada murid tersebut memahami nilai murni yang dinyatakan ataupun tidak. Jika mereka memahami nilai murni tersebut, guru perlu melihat pula dari segi kelakuannya. Adakah mereka tahu cara-cara untuk menerapkan nilai-nilai murni itu dalam tingkah laku mereka? Di sini, guru memainkan peranan yang amat penting dalam mendidik murid-murid untuk sentiasa berkelakuan sopan.

Terdapat sesetengah murid yang suka untuk meremehkan rekan-rekannya yang mengamalkan nilai-nilai murni. Namun begitu, jika guru berupaya untuk mengubah persepsi mereka terhadap nilai murni, maka, berhasillah seorang murid yang beretika dan berkelakuan baik. Guru perlu meminta mereka untuk memberi pandangan tentang nilai-nilai murni dan etika yang harus diterapkan dalam diri mereka, dari segi kesan amalan nilai tersebut terhadap diri, masyarakat, agama dan juga negara.

Guru juga boleh memberi penghargaan kepada murid yang sentiasa mengamalkan nilai-nilai yang dipelajari semasa sesi proses belajar mengajar. Perkara ini boleh menjadi satu kegiatan kepada murid-murid lain untuk bersama-sama mengamalkan nilai-nilai murni dalam kehidupan seharian mereka. Oleh itu, guru perlu kreatif dan kritis dalam mendidik murid-murid untuk menjadikan mereka seorang insan yang berguna dan berkualitas setelah tamat dari sekolah.

Kelas abad ke-21 ini amat sesuai dilaksanakan karena ia banyak memberi impak-impak yang positif dalam diri murid. Dengan wujudnya kelas adalah murid-murid akan dilatih untuk memiliki kemahiran yang boleh digunakan pada masa akan datang, seperti kemahiran komunikasi yang baik, mampu berkolaborasi dan menyelesaikan masalah berdasarkan realiti kehidupan 
dengan unsur-unsur kemahiran berpikir kritis. $^{8}$

\section{Strategi Pembelajaran Pendidikan Kristen yang Efektif}

Terdapat banyak
Pembelajaran dalam proses belajar
mengajar. Meskipun era globalisasi
teknologi begitu meningkat tetap saja
banyak penemuan model-model
pembelajaran sesuai konteks zamannya. Strategi pembelajaran yang sangat populer ialah: strategi Gallery Walk, 3 stray, 1 stay, Jigsaw, Think Pair share, Round Robin, Hot seat, Role play, Inner-Outer Circle, Flying Carpet, Talking Chips, Pembentangan Kumpulan, Simulasi, Sajak, Syarahan, Problem Based Learning, Project Based Learning, dan ratusan bahkan ribuan model. $^{9}$

Untuk menjadi guru yang baik, guru dinilai dalam enam aspek yang perlu dicapai oleh guru yaitu: (1) Guru sebagai perancang, guru harus ada Rancangan Pengajaran Harian. (2) Guru sebagai pengawal, mengelola isi pelajaran masa dan aktiviti kumpulan murid. (3) Guru sebagai pembimbing, memberi tunjuk ajar (panduan) dan mengaitkan isi pelajaran dengan tajuk pelajaran yang lain. (4) Guru sebagai pendorong, memberi rangsangan untuk berfikir dan membuat keputusan dan memberi pujian (penghargaan) kepada murid. (5) Guru sebagai penilai, sesi soal jawab dan hasil akhir belajar dimana guru mesti memberi nilai terhadap hasil kerja

\footnotetext{
${ }^{8}$ Masyuniza Yunos, (2015), "Hubungan sikap dan persepsi murid terhadap pembelajaran Bahasa Melayu dengan kemahiran abad ke-21", Jurnal Malay Language Education, 5(2), 22-30.

${ }^{9}$ Aaron Johnson, (2013), "Effective Methods for 21st Century Learning: A teacher Action Research Project", Meridian: A K-16 School Computer Technologies Journal Jurnal, Vo.6.
}

murid. (6) Murid sebagai pembelajar aktif, aktivitas berpusatkan murid dan kooperatif serta mengaitkan isi pelajaran denga isi sejagat atau tempatan. ${ }^{10}$

Satu kaedah guru-guru (pensyarahpensyarah) boleh lakukan ialah kaedah Flipped Classroom dalam proses belajar mengajar di mana guru-guru akan memberi tajuk lebih awal dan meminta murid mencari bahan-bahan yang berkaitan dengan tersebut dalam internet atau mana-mana sumber. Ini menggalakkan murid-murid agar dapat berdikari berusaha mencari bahan.

Guru-guru agar dapat memutuskan penggunakan model pembelajaran yang tepat bagi konteks tertentu dengan kaidahkaidah sebagai berikut: (1) Berbagai Strategi Proses Belajar Pengajar. Sebagai guru perlu kreatif dalam menggunakan model mengajarnya di kelas. Guru mesti memilih dan menggunakan model pembelejaran yang sesuai dengan konteks masanya. Tujuan model belajar mengajar adalah memberi murid kemahiran yang diperlukan untuk mereka menjadi kritis dan kreatif belajar untuk berkolaborasi dan berkomunikasi menyampaikan idea mereka. Guru diminta supaya tidak terikat dengan satu model strategi pembelajaran sehingga dapat membuat murid menjadi bosan. (2) Beri Masa dan Peluang. Kelancaran aktivitas semasa proses belajar mengajar dibantu oleh berapa banyak kalinya murid dilatih untuk berpikir kritis dan kreatif dapat membentuk "kebaharuan cara berpikir". Maka jangan berputus asa jika guru mrngalami cobaan kegagalan yang pertama. Murid perlu diberi peluang dan masa untuk mereka belajar membentuk kumpulan,

\footnotetext{
${ }^{10}$ Mashira Yahya, (2019) "Praktik Pembelajaran Abad 21 (PAK21) di PT Guru dan Fasilitasi (PdPc) Guru Sekolah Dasar", Jurnal IPDA, No. 26.
} 
melakukan tugasan, membentang dan lainlain. Laburkan sedikit masa sekarang, untuk masa depan yang lebih menyenangkan. (3) Arahan Jelas. Guru memberi sebarang tugasan kepada murid, pastikan arahan jelas disediakan: apa yang perlu ada? Bagaimana perlu dipersembahkan kepada murid? Ini untuk mengelakkan hasil kerja murid yang tidak memuaskan hati guru. Selain itu, arahan murid dengan jelas apa yang mesti ia lakukan. (4) Kepercayaan dan Bimbingan. Memberi kepercayaan dan bimbingan kepada murid. Barulah guru boleh menghasilkan sesuatu yang luar biasa. Belajar untuk beri kepercayaan kepada murid. Percaya dengan kebolehan mereka. Percaya bahwa mereka boleh lakukan, dan bimbing mereka jika perlu. Telah banyak keajaiban dilihat, dengan hanya sedikit kepercayaan. (5) Hak Murid untuk Belajar. Kembalikan semula hak murid untuk belajar. Hak murid untuk mencari dan meneroka ilmu. Rangsang minat dan rasa ingin tahu murid. Seperti selalu, bukan ikan yang hendak diberi, tetapi pancing dengan sendiri, supaya dapat lebih ikan yang mereka boleh pancing selepas ini. Jika ini yang anda amalkan dalam bilik darjah,pasti semua akan berjaya. ${ }^{11}$

\section{Cabaran, Kekangan Melaksanakan \\ Pendidikan Kristen, dan Cara Mengatasinya}

Cabaran besar pendidikan Kristen ialah para pendidik mempunyai tanggungjawab melaksanakan peranan dengan penuh komitmen dan keikhlasan sebagai berikut:

Pertama, para pendidik mampu membina Budaya Ilmu Kemampuan para

\footnotetext{
${ }^{11}$ https://www.gpsbestari.com/tip/tipmengajar/antara-teknik-pembelajaran-abad-21perkongsian-guru-cemerlang.
}

pendidik ialah menyusun, dan mensepadukan ilmu dengan perkembangan semasa, seperti: teknologi dan perkomputeran. Para pendidik seharusnya fokus melangkah dan menggembleng peluang untuk memperlengkapi diri dengan ketrampilan sebagai pemimpin ilmu berasaskan teknologi, bersedia menjurus kepada penguasaan, dan penggunaan teknologi maklumat untuk pelbagai bidang serta menjadi mekanisme urusan harian.

Kedua, para pendidik kemahiran berpikir dan pemikiran konstruktif. Para guru mestinya mendidik para pelajar dengan menggunakan daya pikir tinggi dan terampil untuk melahirkan pelajar-pelajar agar mereka dapat belajar sepanjang hayat dan mempunyai modal intelektual tinggi menghadapi era globalisasi. Kemahiran berpikir dan pemikiran konstruktif perlu juga terarah kepada pandangan jauh dan luar biasa.

Ketiga, para pendidik kemampuan menterjemah dan mengembangkan kurikulum yang luwes. Para pendidik seharusnya mempunyai kemahiran dan ketrampilan mengaitkan domain teori dengan praktis dan mesti bijak membina pengetahuan dan kemahiran secara developmental mengikut kadar pembelajaran (pace of learning) untuk mencapai kemahiran thoughtful learning. Kurikulum sepatutnya mempunyai ruang untuk disesuaikan dengan perkembangan semasa berdasarkan keperluan negara, perkembangan semasa dan kemajuan sejagat. Kurikulum yang hendak digubal melalui Four Pillars of Learning yaitu: (a) Learning to know (Belajar untuk menguasai ilmu), (b) Learning to do (Belajar untuk menguasai kemahiran), (c) earning to be (Belajar untuk menjadi insan berguna), dan 
(d) learning to live together (Belajar untuk harmoni dan bekerjasama). ${ }^{12}$

Keempat, para pendidik mampu menerapkan nilai-nilai murni (moral, akhlak). Nilai-nilai murni menitikberatkan perlakuan baik, peradaban dan tatasusila insan dalam hubungannya sesama manusia, alam dan Tuhan. Elemen ini sangat penting dalam usaha pembudayaan masyarakat yang dapat mewujudkan kesejahteraan dan keharmonian negara.

Kelima, para pendidik mampu menguasai pengetahuan dan kemahiran industri. Para pendidik melahirkan generasi untuk pasaran tenaga kerja industri merupakan Dasar Pembangunan Negara. Usaha ini ialah sebagai sumbangan kepada melahirkan sumber manusia yang menyumbang kepada tenaga buruh yang berkualitas, sebab boleh dan responsif kepada perubahan keadaan perindustrian. Kurikulum dan daya didik di dalam sistem pendidikan hendaklah berupaya merealisasikan masyarakat sainstifik, teknologis dan progresif yang inovatif dan berpandangan jauh ke hadapan.

Keenam, para pendidik mampu membentuk Masyarakat Madani Pendidik yang profesional dapat menangani pengajaran dan pembelajaran yang dapat membudayakan masyarakat dengan amalan akhlak dan nilai-nalai murni. Perkembangan dan kemajuan dunia boleh mempengaruhi gaya hidup dan akhlak masyarakat. Usaha mengimbangkan perkembangan dan kemajuan dunia aspek teknologi maklumat dan industri hi-tech, dengan pembentukan rohaniah dan ketahanan diri diberikan perhatian serius. Maka konsep masyarakat

${ }^{12}$ Schumaker (eds.), Teaching Adolescents with Disabilities: Accessing the General Education Curriculum (Thousand Oaks, CA: Corwin Press, 2006), 121. madani merupa wadah untuk membudayakan masyarakat Malaysia. Kurikulum dalam sistem pendidikan sama ada secara formal atau tidak formal, mampu menyusun dan membentuk masyarakat madani.

Dalam merancang pelaksanaan konsep ini beberapa perkara mesti diberikan perhatian: (1) Prinsip berteraskan keimanan dan moral yang menjamin keseimbangan antara kekebasan perseorangan dengan kestabilan dan kesejahteraan masyarakat. (2) Mendorong perkembangan indidvidu dari segi pemikiran, budaya, sosial, ekonomi, alam sekitar dan teknologi. (3) Sistem sosial yang cakap, saksama, dan perlaksanaan pemerintahan mengikut undang-undang serta bukan nafsu atau kepentingan individu. (4) Mengamalkan akhlak terpuji dan boleh diteladani. Konteks ini berusaha mewujudkan masyarakat madani diharap dapat melahirkan warga negara yang berpegang kepada teras keimanan dan ketuhanan, mempunyai ketahanan diri, memiliki identiti bangsa Malaysia, tahap kepimpinan yang dinamik, berpandangan jauh, kreatif dan inovatif, citra diri yang tinggi, berdisiplin dan amalan hidup yang cemerlang. Kesimpulan Perkembangan dunia aspek ekonomi, sosial, politik dan teknologi seharusnya menjadi indikator asas kepada sistem pendidikan dan persekolahan untuk memenuhi keperluan tenaga manusia yang berteraskan keilmuan yang berkualiti, asas nilai dan moral yang berdasarkan kepercayaan kepada Tuhan, semangat patroit dan memelihara perpaduan rakyat sebagai bangsa Malaysia, dan manusia yang bertaraf dunia. Para pendidik adalah wahana yang boleh menentukan corak manusia yang mampu menghadapi alaf baru, abad ke-21. (5) Selain daripada itu cabaran seperti kekangan masa, isi 
kandungan terlalu berat, peralihan tampuk kepimpinan, amalan pengajaran guru yang tradisional dan guru-guru tak mau mengubah sikap dan menyahut cabaran, ramai guru yang veteran tidak mahir dalam teknologi dan tidak minat mempelajari perkara baru.

Untuk mengatasi cabaran-cabaran tersebut, guru-guru (pensyarah-pensyarah) harus melengkapi mereka dengan ilmu pengetahuan dan kemahiran Pendidikan Kristen adalah: (1) para guru memberi pengetahuan dan kemahiran diri yang tinggi.(2) Guru mampu membuat modul pembelajaran, sumber dan kemudahan lain mesti disediakan. (3) Guru harus sentiasa dilatih supaya mereka mampu mengembangkan strategi pembelajaran yang sesuai konteks. (4) Guru harus diberi latihan profesionalisme oleh pakar-pakar yang boleh mendorong dan membimbing mereka. $^{13}$ Inti dari semua ini adalah pencapaian murid sentiasa menjadi ukuran kepada keberhasilan proses pembelajaran yang dialami murid dalam kelas. Hal ini karena proses belajar mengajar sangat bermakna membantu murid meningkatkan minat dan motivasi mereka untuk mengamalkan pembelajaran sepanjang hayat. Bagi mencapai aspirasi pendidikan negara, keberhasilan guru menjadi salah satu anjakan transformasi terkini. ${ }^{14}$

Bagi cabaran seperti kekangan masa kuliah di seminari boleh kurangkan aktivitas informal dan tumpukan masa kepada proses

\footnotetext{
${ }^{13}$ Nurzarina Amran \& Roslinda Rosli (2017), "Kefahaman Guru Tentang Kemahiran Abad Ke-21" (Malaysia: Fakulti Pendidikan, Universiti Kebangsaan Malaysia), diakses pada 15 April 2019, http://conference.kuis.edu.my.

${ }^{14}$ Ainun Rahman Iberahim, dkk., (2017). "Pembelajaran Abad ke-21 dan Pengaruhnya terhadap Sikap, Motivasi dan Pencapaian Bahas Melayu Pelajar Sekolah Menengah", Jurnal Pendidikan Bahasa Melayu, Vol. 7(2) 77-88.
}

belajar mengajar. Isi kandungan yang terlalu padat boleh dikurangkan mengikut kepentingan subjek dan yang golongan veteran yang berpegang kepada "old habits die hard" mereka perlu diberi motivasi dan kesadaran untuk memajukan diri melalui training yang lebih menyeronokan.

\section{KESIMPULAN}

Pendidikan Kristen merupakn proses pembelajaran yang berpusatkan murid berteraskan elemen komunikasi, kolaboratif, pemikiran kritis, kreativiti, dan aplikasi nilai murni dan etika.

Strategi pembelajaran Pendidikan Kristen dapat dilakukan sesuai dengan konteks murid di kelas dengan kaidahkaidah sebagai berikut: guru menentukan strategi proses belajar pengajar, guru beri masa dan peluang, guru memberikan arahan jelas kepada murid, guru memberi kepercayaan dan bimbingan kepada murid, dan guru memberikan hak murid untuk belajar.

Cabaran dan kekangan melaksanakan Pendidikan Kristen dan cara mengatasinya adalah: Pertama, guru-guru (pensyarah-pensyarah) perlu sadar akan kepentingan mempelbagaikan kaedah pengajaran dan pembelajaran agar selari dengan pendidikan abad ke-21 dalam menunaikan tugas dan tanggungjawab mereka demi kemenjadian murid. Penekanan dalam menguasai kemahiran era globalisasi melalui proses belajar mengajar haruslah bermula dengan menerapkan konstruk kemahiran teknologi. Kedua, guru harus sentiasa bersikap proaktif, menilai diri, bersedia, berkeyakinan dan mengambil inisiatif untuk berusaha meningkatkan kemahiran dan menghasilkan teknik pengajaran berkesan yang mampu menarik 
minat murid. Ini adalah penting untuk menyediakan murid menghadapi cabaran "the real world" adalah mempunyai kebolehan holistik.

\section{DAFTAR PUSTAKA}

Amran, Nurzarina \& Rosli, Roslinda. (2017), "Kefahaman Guru Tentang Kemahiran Abad Ke-21". Malaysia: Fakulti Pendidikan, Universiti Kebangsaan Malaysia. diakses pada 15 April 2019, http://conference.kuis.edu.my.

GP, Harianto. (2016), "Quality Learning Cooperative With Pattern Collaborative to Improve the Character", Jurnal Tekpen, 1(1), 146.

GP, Harianto. Teologi PAK. Yogyakarta: Andi, 2017.

https://www.gpsbestari.com/tip/tipmengajar/antara-teknikpembelajaran-abad-21perkongsian-guru-cemerlang.

https://www.pendidik2u.my/pembelaja ran-abad-ke-21-pak21/.

Iberahim, Ainun Rahman Iberahim, dkk. (2017). "Pembelajaran Abad ke-21 dan Pengaruhnya terhadap Sikap, Motivasi dan Pencapaian Bahas Melayu Pelajar Sekolah Menengah", Jurnal Pendidikan Bahasa Melayu, Vol. 7(2) 77-88.

Johnson, Aaron. (2013), "Effective Methods for 21st Century Learning: A teacher Action Research Project", Meridian: A K-16 School Computer Technologies Journal Jurnal, Vo.6.

Malaysia (2013), "Pelan Pembangunan Pendidikan Malaysia 2013-2025" (Putrajaya: Bahagian Pembangunan Kurikulum), https://www.imls.gov.

Russel, B.H. Social Research Methods: Qualitative and Quantitative Approaches. Thousand Oaks, CA: Sage Publications, 2000.
Schumaker (eds.), Teaching Adolescents with Disabilities: Accessing the General Education Curriculum. Thousand Oaks, CA: Corwin Press, 2006.

Schumaker, J.B. \& Deshler, D.D. "Teaching Adolescents to be Strategic Learners", Teaching Adolescents with Disabilities: Accessing the General Education Curriculum. Thousand Oaks, CA: Corwin Press, 2006.

Shukor, Nur Syahfika Abdul \& Harun, Zolkepli. "Cabaran Penerapan Pembelejaran Abad ke-21 dalam Mata peljaran Sains", Procesing 1(43) (Malaysia: Fakulti Pendidikan Universiti Kebangsaan Malaysia).

Yahya, Mashira. (2019) "Praktik Pembelajaran Abad 21 (PAK21) di PT Guru dan Fasilitasi (PdPc) Guru Sekolah Dasar", Jurnal IPDA, No. 26.

Yunos, Masyuniza. (2015), "Hubungan sikap dan persepsi murid terhadap pembelajaran Bahasa Melayu dengan kemahiran abad ke-21", Jurnal Malay Language Education, 5(2), 22-30. 